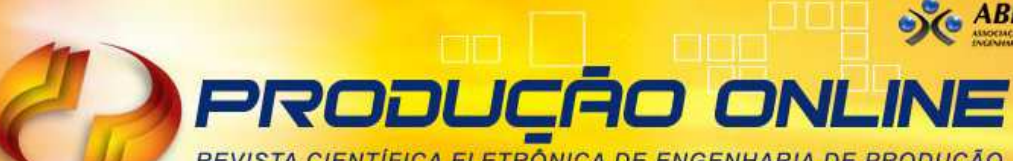 REVISTA CIENTIFICA ELETRŌNICA DE ENGENHARIA DE PRODUÇÃO \\ ISSN 1676-1901
}

\section{SUSTENTABILIDADE E VANTAGEM COMPETITIVA ESTRATÉGICA: UM ESTUDO EXPLORATÓRIO E BIBLIOMÉTRICO}

\section{SUSTAINABILITY AND STRATEGIC COMPETITIVE ADVANTAGE: AN EXPLORATORY AND BIBLIOMETRIC STUDY}

\author{
Pedrita Dantas Gabriele* E-mail: pedritadantas@gmail.com \\ Fernanda Tavares Treinta* E-mail: fernandatreinta@gmail.com \\ José Rodrigues de Farias Filho* E-mail: rodrigues@labceo.uff.br \\ Maurício Corrêa de Souza* E-mail: mauriciocsouza@yahoo.com.br \\ Pâmela Botelho Tschaffon* E-mail: pamtschaffon@yahoo.com.br \\ Sonia Regina Brantes* E-mail: sonia brantes@yahoo.com.br \\ *Universidade Federal Fluminense, Niterói, RJ
}

Resumo: O presente estudo tem como objetivo realizar uma análise bibliométrica a fim de entender o estado da arte da produção acadêmica que relaciona sustentabilidade com estratégia e vantagem competitiva. Para isso, o artigo busca identificar o que foi produzido, publicado e gerado de conhecimento pela comunidade científica relacionada ao tema, além de analisar suas principais tendências, através de uma análise quantitativa da evolução da produção científica sobre os temas, veículos de publicação, centros de pesquisa, principais pesquisadores e redes de estudo. Inicialmente foi construída uma árvore de palavras-chave com o intuito de pesquisar nos motores de busca publicações sobre o tema e posteriormente, fazer o tratamento e análise dos dados com 0 apoio dos softwares EndNotes ${ }^{\circledR}, \operatorname{RefViz}{ }^{\circledR}$ e Excel ${ }^{\circledR}$. Através da pesquisa, constatou-se que houve um aumento recente das publicações sobre o tema deste artigo, principalmente a partir do ano 2000 , sendo que as áreas da ciência que mais publicaram sobre o assunto são as representadas pelo Triple Bottom Line (ambiental, social e econômica), destacando-se que a sustentabilidade está tendo atualmente um viés muito mais proativo ao invés de reativo. Além disso, foi também possível identificar que os países que possuem os melhores índices de desenvolvimento, tal qual o IDH e o índice GINI, são os pioneiros na publicação deste tema.

\section{Palavras-chave: Sustentabilidade. Estratégia. Vantagem Competitiva. Bibliometria}

\begin{abstract}
This study aims to conduct a bibliometric analysis to understand the state of the art of academic research that relates to sustainability strategy and competitive advantage. For this, the article seeks to identify what is produced, released and knowledge generated by the scientific community related to the subject, and analyzing key trends, through a quantitative analysis of the evolution of scientific literature on the themes, vehicles publishing, centers research, leading researchers and research networks. Initially we constructed a tree of keywords in order to quest the search engines and publications on the subject and later, do the processing and analysis software with the support of EndNote $\AA$, RefViz $\AA$ and Excel $\AA$.Through research, we found that there was a recent increase of publications on the subject of this article, especially since 2000 , and the areas of science that most published on the subject are represented by the Triple Bottom Line (environmental, social and economic), pointing out that sustainability is currently having a bias much more proactive instead of reactive. Furthermore, it was also possible to identify countries that have the highest rate of development, like the HDI and GINI index, are the pioneers in publishing this issue.
\end{abstract}

Key-words: Sustainability. Strategy. Competitive Advantage. Bibliometry.

Revista Produção Online, Florianópolis, SC, v.12, n. 3, p. 729-755, jul./set. 2012. 


\section{INTRODUÇÃO}

Nos últimos anos, os impactos sociais e ecológicos causados pela globalização têm sido um tema recorrente. A nova economia está produzindo uma multiplicidade de consequências desastrosas - o aumento da desigualdade social, o fim da democracia, a deterioração rápida e extensa do ambiente natural e o aumento da pobreza. Está cada vez mais claro que o capitalismo global, na forma em que se encontra hoje, é insustentável (CAPRA, 2005) e por isso, segundo Gandhi, Selladurai e Santhi (2006), a legislação, os consumidores e a comunidade configuram cada vez mais uma força para a adesão das empresas aos benefícios ambientais e sociais.

Concomitantemente, segundo Kim e Mauborgne (2005), à medida que o espaço no mercado fica mais restrito, as perspectivas de lucro e crescimento ficam cada vez menores. Por isso, conforme Porter (1993), as empresas devem analisar as condições de seus fatores de produção, da demanda interna e suas consequências sobre a demanda externa, a influência das indústrias correlatas e de apoio, além da influência da estrutura e da rivalidade das empresas no mercado interno e externo, para alcançar vantagens competitivas de longo prazo.

Dentro deste contexto, a sustentabilidade começa a transformar o cenário competitivo, o que obriga as empresas a analisar de outra maneira os seus produtos, processos e modelos de negócio (NIDUMOLU, PRAHALAD, RANGASWAMI, 2009). Segundo Fujihara (2010), ao criar uma cadeia de valor sustentável, ou seja, que dê igual prioridade aos objetivos econômicos, ambientais e sociais, a empresa consegue reduzir custos e riscos, aumentar a qualidade, além de encontrar novas oportunidades de negócios e desenvolver a preferência do cliente.

Exemplos de empresas que alcançaram vantagens competitivas por meio de valores, crescimento, boas práticas gerenciais e compromisso em relação à sustentabilidade são percebidos com regularidade. Como exemplo, tem-se a empresa Cisco, que segundo Nidumolu, Prahalad, Rangaswami (2009), reaproveitava os equipamentos que retornavam do cliente em uma média de $5 \%$. Ao tornar esse processo de reciclagem uma unidade de negócio da empresa, com metas e demonstrativos de resultados claros, o reaproveitamento passou a ser de $45 \%$ dos produtos, os custos de reciclagem da empresa reduziram em $40 \%$ e a 
divisão se tornou um centro de lucro que, em 2008 contribuiu com U\$100 milhões para os resultados da empresa.

Ainda nesse sentido, Porter (2010) destaca que a área de responsabilidade social vivenciou dois estágios principais: No primeiro, as empresas entendiam a área de responsabilidade social apenas como forma de responder às pressões políticas, onde se destaca o exemplo da Nike, em que na década de 90 teve grande queda de vendas e desvalorização da marca após os consumidores de todo o mundo tomarem conhecimento da relação entre Nike e fornecedores da Indonésia, principalmente no que diz respeito á utilização do trabalho infantil (PORTER, 2010). As empresas nesse período tomavam diversas ações de responsabilidade social, porém apenas com o objetivo de sanar questões específicas, e não de forma voluntária.

Já no segundo momento, as empresas passaram então a ter uma postura proativa em relação à responsabilidade social, uma vez que as iniciativas nesse contexto possibilitavam um retorno financeiro e serviam de instrumento para construção da imagem da empresa. Dessa forma, empresas como a General Electric e a Unilever passaram a incorporar elementos de sustentabilidade à sua própria estratégia, atingindo assim um grande diferencial competitivo.

Essa postura proativa em relação à sustentabilidade também é reforçada devido aos impactos negativos que as empresas podem sofrer caso não estejam alinhadas a esses conceitos. Esse é o caso da companhia petrolífera British Petroleum, em que após a explosão de uma plataforma e o vazamento de petróleo no Golfo do México, a empresa gastou até agosto de 2010, aproximadamente US\$ 428 milhões com indenização, US\$ 93 milhões com publicidade, além dos valores das multas e dos investimentos feitos para conter o vazamento. De acordo com a divulgação da própria companhia, estima-se que neste mesmo período, a empresa teve US\$32,2 bilhões em custos relacionados ao desastre. Consequentemente, a empresa teve danos dificilmente mensuráveis à sua imagem, além de uma queda brusca de suas ações na bolsa de valores (BRITISH PETROLEUM, 2010).

A partir desse cenário, torna-se extremamente relevante entender de que forma a pesquisa acadêmica tem acompanhado esta discussão e evoluído na produção científica que correlaciona os temas de sustentabilidade e vantagem competitiva estratégica. Nesse sentido, a realização de uma análise bibliométrica 
torna-se relevante para identificar esses fatores e entender de que forma a produção acadêmica tem acompanhado a discussão desses temas.

\section{PROBLEMA E OBJETIVO DO ESTUDO}

O presente estudo tem como objetivo realizar uma análise bibliométrica a fim de entender o estado da arte da produção acadêmica que trata a sustentabilidade como um meio de aumentar a competitividade das empresas. Para isso, o artigo busca identificar o que foi produzido, publicado e gerado de conhecimento pela comunidade científica relacionado ao tema, além de analisar suas principais tendências.

Dessa forma, as questões de pesquisa que se pretende responder são acerca do crescimento das publicações na linha do tempo, das áreas de ciência mais envolvidas nas publicações e das palavras-chave mais utilizadas pelos autores. Além disso, serão listados os principais veículos, países e instituições de pesquisa que publicam artigos sobre este tema. Por fim, serão apresentados os principais autores tidos como referência para a produção de artigos e como se constitui o desenvolvimento das redes de estudo, grupos de pesquisa e parcerias entre instituições para atender esta nova demanda da sociedade. Sendo assim, os objetivos específicos desse artigo podem ser divididos em quatro eixos principais:

(I) Evolução da produção científica: identificar a evolução dos artigos publicados sobre o tema sustentabilidade como uma vantagem competitiva para as empresas, visualizar a distribuição dos artigos por área da ciência e verificar as palavras-chave mais citadas pelos autores.

(II) Veículos de publicação e centros de pesquisa: analisar as principais instituições ofertantes e os veículos que mais publicaram sobre o assunto.

(III) Pesquisadores: identificar os pesquisadores tidos como principais referências nas pesquisas.

(IV) Redes de Estudo: analisar possíveis parcerias e redes para o estudo do tema.

Por se tratar de uma pesquisa científica teórica com base em uma amostra que proporciona uma visão holística sobre as produções acadêmicas da sustentabilidade como uma vantagem competitiva, este artigo não pretende fornecer 
uma análise detalhada da implementação deste tema. Sendo assim, sua contribuição fundamental consiste no auxilio ao entendimento do ambiente científico em que este assunto se insere, permitindo o embasamento de estudos futuros nesta área.

\section{METODOLOGIA}

Em relação aos aspectos metodológicos, o presente estudo pode ser classificado segundo sua finalidade, objetivos e natureza. Quanto a sua finalidade, a pesquisa caracteriza-se como teórica, na medida em que objetiva gerar conhecimento para o esclarecimento de um problema específico, por meio de uma base bibliográfica. Já em relação aos seus objetivos, a pesquisa caracteriza-se como exploratória onde sua aplicação tem como intuito conhecer a variável de estudo tal como se apresenta, seu significado e o contexto onde ela se insere. Sob a perspectiva de sua natureza, a pesquisa é classificada como quantitativa, já que a metodologia desenvolvida é baseada em procedimentos estatísticos, com raciocínio lógico e dedutivo.

Para o alcance dos resultados foi desenvolvida uma metodologia que conta com cinco etapas principais: (1) Estruturação da pesquisa, (2) Coleta de artigos, (3) Refinamento da amostra, (4) Tabulação e análise de dados e (5) Resultados e conclusões. Tais etapas podem ser visualizadas através da Figura 1 abaixo e serão detalhadas posteriormente.

Figura 1 - Etapas da metodologia

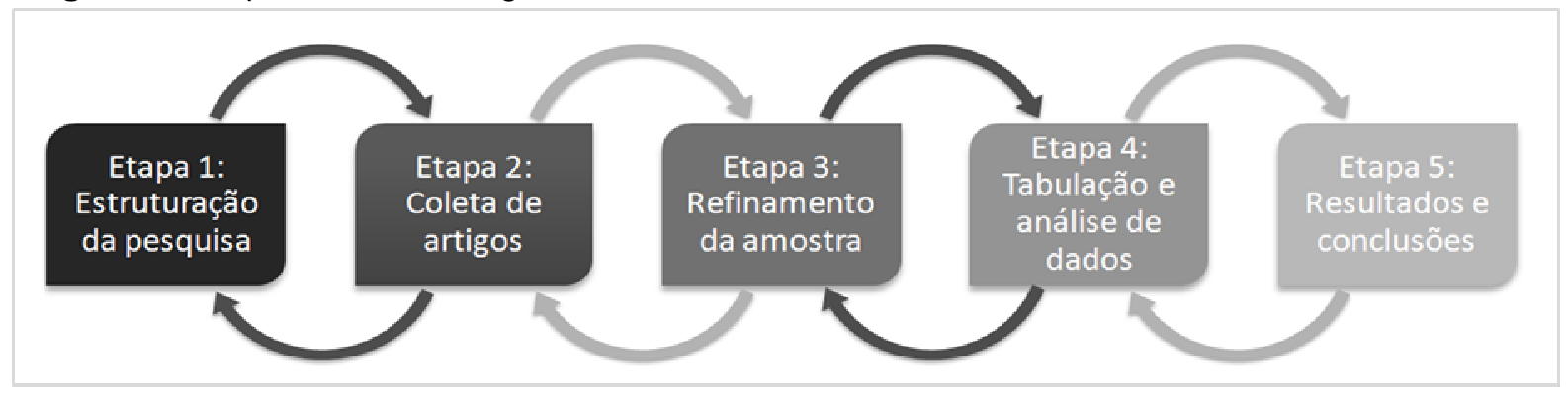

Fonte: Elaborado pelos autores

Vale ressaltar que a metodologia proposta representa um processo dinâmico e cíclico, tendo em vista que estará sempre se modificando. Em função da própria 
pesquisa e dos resultados encontrados ao longo do estudo, as etapas anteriores podem ser revistas e os próprios resultados podem ser aperfeiçoados.

\section{1aㅡ. Etapa: Estruturação da pesquisa}

Com base em publicações de artigos, livros, teses e dissertações acerca dos temas "sustentabilidade" e/ou "vantagem competitiva", foi desenvolvida uma árvore de palavras-chave que pode ser observada na Figura 2 abaixo. Este levantamento teve como objetivo estruturar a busca direcionada de artigos na base de publicações dos periódicos da CAPES (Coordenação de Aperfeiçoamento de Pessoal de Nível Superior).

Para a construção desta árvore de palavras-chaves, foi feita uma avaliação dos objetivos de pesquisa para estruturar o arcabouço teórico do estudo. Nesse sentido, a elaboração da árvore de decisão tem como finalidade desdobrar as palavras ou termos mais importantes para a pesquisa no sentido horizontal e vertical com diferentes propósitos.

No sentido vertical, apresenta-se uma divisão dos objetivos em áreas temáticas concêntricas e distintas que permitam que a pesquisa seja abrangente e, consequentemente, relevante em termos de exploração bibliográfica. Já no sentido horizontal, a subdivisão das áreas temáticas em ramos interdependentes garante a profundidade da pesquisa, permitindo também a especialização em relação aos temas abordados (FARIAS FILHO, 2009).

\section{2ª etapa: Busca de artigos}

Após a estruturação dos termos-chave, iniciou-se a exploração propriamente dita utilizando a lógica booleana com os conectivos "E" e "OU" nas combinações das palavras-chave. Neste momento, procurou-se saturar os artigos da base dos periódicos CAPES, por meio dos motores de busca ISI Web of Knowledge e Scopus, somando um total de 7.000 artigos pesquisados. A data final da pesquisa nos motores de busca foi 21/12/2009, sendo assim, o banco de dados de artigos para o 
estudo exploratório e bibliométrico contempla apenas publicações existentes até esta data mencionada.

Figura 2 - Diagrama de palavras-chave

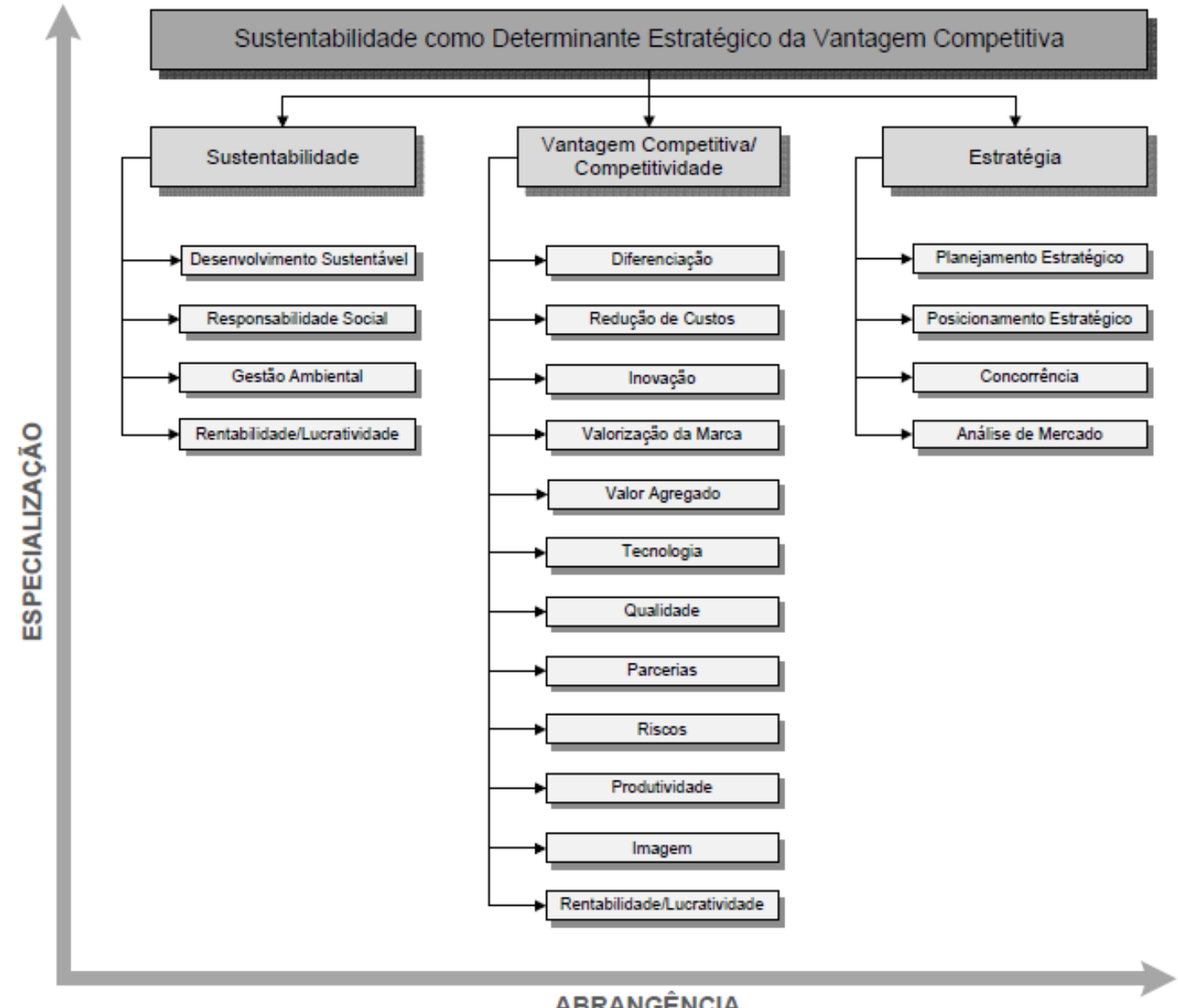

Fonte: Elaborado pelos autores

A base de dados foi administrada com o auxílio do software EndNotes $\AA$, que possui recursos para sinalizar as publicações com informações incompletas. Esses artigos foram retirados da amostra, reduzindo-a para um total de 5.115 artigos.

\section{3a etapa: Refinamento da amostra de artigos}

A partir da formação da base de artigos com as informações completas, foi utilizado o software RefViz® para o refinamento da amostra. Esse programa utiliza a formação de clusters de artigos com base em termos com maior frequência de 
citação pelos autores. A partir dessa lista de termos, o pesquisador classifica as palavras conforme sua maior e menor importância, conforme os objetivos da pesquisa. Em seguida, são geradas galáxias que representam a interação entre os termos dos artigos, nos quais os com menor relevância aos objetivos desse estudo foram excluídos da amostra. Esse processo foi realizado repetidas vezes até encontrar uma distribuição com alta correlação, obtendo-se ao final uma base de 117 artigos.

\section{4ª etapa: Tabulação e análise de dados}

Após o refinamento da base de artigos, foram tabulados os seguintes quesitos dos documentos: autores, instituições, ano de publicação, citações, veículo de publicação, fator de impacto JCR (Journal Citation Report), país de origem do veículo de publicação, país de origem das instituições ofertantes, área da ciência e setor econômico. Posteriormente foram gerados gráficos e análises desses dados, de forma a responder às questões de pesquisa propostas neste estudo.

\section{5ª etapa: Resultados e Conclusões}

Finalmente, torna-se possível extrair os resultados e conclusões referentes à pesquisa bibliométrica a respeito do tema. Nessa etapa, os resultados foram identificados de acordo com os objetivos da pesquisa, sendo apresentados segundo os quatro grupos principais expostos anteriormente: (i) Evolução da produção científica, (ii) Veículos de publicação e centros de pesquisa; (iii) Pesquisadores e (iv) Redes de estudo.

\section{FUNDAMENTAÇÃO TEÓRICA}

\subsection{Estudo Bibliométrico}

De acordo com Pao (1989), o termo bibliometria refere-se a uma área de estudo que utiliza a estatística e a matemática com o intuito de quantificar os 
processos de comunicação escrita, tornando possível desta forma que sejam feitas investigações que tenham como base análises quantitativas. Além disso, o autor também destaca a diversidade tanto de leis quanto de conceitos intrínsecos a esse tema.

No Brasil, Araújo (2006) abordou a discussão sobre bibliometria e relaciona o seu surgimento, no início do século passado, com a necessidade do estudo e da avaliação das atividades de produção e comunicação científica. Nesse sentido, a bibliometria tem como finalidade central a utilização de métodos quantitativos que visa gerar uma avaliação objetiva da produção científica.

Nesse contexto, a bibliometria permite a construção de indicadores que possam embasar essa avaliação, possibilitando assim uma análise quantitativa consistente das publicações mais interessantes sobre determinado assunto.

O estudo bibliométrico pode ser dividido em descritivo e inferencial. A abordagem descritiva tem como intuito analisar as informações obtidas através dos dados da base bibliográfica e apresentá-las em termos descritivos, por meio de indicadores quantitativos gerados diretamente da amostra. De forma complementar, a bibliometria inferencial busca entender, em função das informações obtidas através da base bibliográfica, alguns aspectos sobre a relevância, abrangência e qualidade dos conceitos e seus respectivos autores. Para isso, utiliza diversas leis bibliométricas a fim de gerar conclusões a partir de uma amostra selecionada do total da população. (FARIAS FILHO, 2009).

Desta forma, destaca-se que este estudo tem como propósito analisar gráficos e indicadores gerados a partir do tratamento do banco de dados de uma amostra de artigos selecionados. Sendo assim, a pesquisa bibliométrica neste trabalho possui uma abordagem descritiva e teve como intuito principal auxiliar no entendimento das discussões atuais sobre os temas "sustentabilidade" e "vantagem competitiva estratégica", de forma a identificar o que já foi produzido, publicado e gerado de conhecimento pela comunidade acadêmica, além de entender de que forma esses estudos evoluíram ao longo do tempo e quais as tendências que apresentam. 


\subsection{Histórico da Sustentabilidade}

Segundo Daily e Huang (2001), com a revolução industrial em meados do século XVIII, o desenvolvimento tecnológico emergiu de forma cada vez mais acelerada ao longo das décadas, desencadeando em um profundo impacto no processo produtivo em nível econômico, social e ambiental. Por isso, conforme enunciado por Gandhi, Selladurai e Santhi (2006), quatro principais forças passaram a emergir ao longo do tempo em prol de um ambiente sustentável, são elas: as forças regulatórias, dos clientes, da comunidade e do benefício financeiro.

Inicialmente, a comunidade exercia pressões pontuais e voltadas à responsabilidade social, na qual a Europa foi o continente pioneiro. Na década de 70, na França, houve o primeiro movimento social que desencadeou uma responsabilidade legal para as empresas. Nesse período, as organizações com mais de 300 funcionários passaram a ter a obrigação de publicar balanços de suas ações sociais (ETHOS, 2010). Em seguida, foram geradas diversas iniciativas das quais vale destacar o primeiro momento em que se teve uma preocupação oficial da sociedade moderna com as consequências do desenvolvimento não sustentável sob suas diversas perspectivas. Essa preocupação se traduziu por meio da elaboração do Relatório de Brundtland na década de 80. Desenvolvido pela Comissão Mundial sobre o Meio Ambiente e Desenvolvimento, o relatório definiu o conceito de sustentabilidade como suprir as necessidades da geração presente sem afetar a habilidade das gerações futuras de suprirem as suas.

Com isso, foram desenvolvidas diversas práticas para mobilizar, sensibilizar, padronizar e apoiar às empresas a administrarem os seus negócios em bases sustentáveis. Dentre essas práticas se encontra a Segunda Conferência das Nações Unidas sobre Meio Ambiente e Desenvolvimento (CNUMAD), ou Eco-92, que contou com a participação de 179 países e resultou em uma série de convenções, acordos e protocolos (VIOLA, 2008). Dentre seus resultados, encontra-se a "Agenda 21", que consiste em um instrumento que rompe o paradigma sobre o conceito de desenvolvimento, que passa a também abordar questões socioambientais junto ao crescimento econômico (JOHN, SILVA, AGOPYAN, 2001). Desta forma, cada país ficou responsável por elaborar a sua Agenda 21, onde devem ser desenvolvidos 
planos de ação locais, regionais e globais integrados, com base nas diretrizes gerais do movimento. Segundo Günther (2000), neste momento, houve um forte destaque sobre a necessidade urgente de se implementar um adequado sistema de gestão ambiental para os resíduos gerados pelas indústrias.

Além disso, a partir da Eco-92, a proteção ao meio ambiente passou a ser tema para as normas internacionais. Nesse período foi estabelecida a criação de um grupo para elaboração de uma série de normas de gestão ambiental junto à ISO, a exemplo do trabalho realizado para a gestão da qualidade com a ISO 9000 (ABNT, 2004). Com o decorrer do tempo, e do consequente aumento da preocupação da sociedade com a sustentabilidade, essas normas e certificações passaram a se transformar em barreiras comerciais, tendo impactos significativos no mercado e na rentabilidade das cadeias produtivas (FIESP, 2010).

As consequências desse impacto podem ser percebidas devido à crescente busca dos investidores por organizações sustentáveis, já que se acredita que essas empresas geram valor para o acionista em longo prazo, pois estão mais preparadas para enfrentar riscos econômicos, sociais e ambientais (BOVESPA, 2008). Conforme destacado no relatório do Social Investment Forum Foundation (2009), de 1995 a 2007, houve um crescimento de 320\% em Investimentos Socialmente Responsáveis (SIFF, 2010), com isso, diversas instituições financeiras se mobilizaram como, por exemplo, a criação do Índice Dow Jones Sustentável (DJSI), em 1999, que avalia mais de 2.500 empresas no mundo (SAM GROUP, 2008). Já no Brasil, em 2005, a Bolsa de Valores de São Paulo (BOVESPA) desenvolveu o Índice de Sustentabilidade Empresarial ou ISE (BOVESPA, 2008). Esse índice tem por objetivo medir o retorno de uma carteira composta por ações de empresas comprometidas com a sustentabilidade, promover práticas sustentáveis no meio empresarial brasileiro e, ainda, servir como benchmark para os fundos de SRI (ISE, 2010).

Outra tendência que pode ser destacada é o crescimento de organizações que direcionam e até mesmo certificam as empresas quanto à adesão às ações sustentáveis, tais quais o Pacto Global e o Global Reporting Initiative (GRI). O Pacto Global é uma iniciativa desenvolvida no ano 2000 pela Organização das Nações Unidas (ONU), que objetiva mobilizar a comunidade empresarial internacional no 
desenvolvimento de um mercado global mais inclusivo e igualitário, por meio de dez princípios gerais (PACTO GLOBAL, 2010). Já o GRI é uma instituição global criada em 1997, responsável pela elaboração de normas mundiais de apresentação de Relatórios de Sustentabilidade. Neles são divulgados princípios e indicadores que as organizações podem utilizar como base para mensurar e publicar os seus desempenhos econômicos, ambientais e sociais. O objetivo é que estes Relatórios de Sustentabilidade venham a se tornar rotineiros e passíveis de comparação (GRI, 2010).

No ano de 2002, a Cúpula Mundial sobre Desenvolvimento Sustentável, chamada também de Rio Mais 10, ocorrida em Johanesburgo (África de Sul), aprofundou o conceito de sustentabilidade. Este conceito foi intitulado "Triple Bottom Line" ou Tripé da Sustentabilidade, onde enfatiza que um ambiente sustentável é amparado de forma sistêmica pela interação entre os pilares ambientais, sociais e econômicos. Esta é a definição de sustentabilidade utilizada neste trabalho como premissa para análise dos resultados.

Enfim, todas essas ações listadas ao longo do tempo apontam para o crescente despertar da sociedade à importância da sustentabilidade. Com isso, Fortes (2006) aponta para a necessidade das organizações apresentarem um perfil sustentável, buscando a excelência do desempenho por meio de uma gestão sistêmica e, desta forma, obter o atendimento das normas legais, a maximização de resultados, o encantamento dos clientes e o atendimento das expectativas das demais partes interessadas.

\subsection{Estratégia}

No contexto atual existe uma grande discussão a respeito dos conceitos de estratégia, fazendo com que esse tema tenha inúmeras interpretações e abordagens. Porter (1993) aborda a estratégia competitiva, que tem como intuito decidir entre um diferente arranjo de atividades para entregar algo de valor único aos consumidores, estabelecendo assim uma posição estratégica e diferenciada no ambiente em que está inserida. Esse posicionamento estratégico pode ter como base três diferentes fontes: variedade de produtos e serviços, atendimento às 
necessidades inerentes a determinado grupo de clientes e especificidades de modalidades de acesso de um grupo específico de consumidores. A partir desses fatores, os quais não são mutuamente excludentes, a empresa pode então criar e estabelecer um posicionamento único frente aos seus concorrentes.

Além disso, existem também outras definições do conceito de estratégia, que pode então ser entendida como um modelo ou plano integrador entre os objetivos e políticas da empresa com suas ações. Nesse contexto, Mintzberg (2000) estabelece ainda que o conceito de estratégia pode ser entendido a partir dos 5Ps da estratégia, sendo eles: estratégia como um plano, como um padrão, como uma posição, como uma perspectiva e como uma interação. Sendo assim, na visão de Mintzberg e Quinn (1996), o conceito de estratégia pode ser definido da seguinte forma:

\footnotetext{
Uma estratégia é um padrão ou um plano que integra as metas maiores da organização, políticas, e a sequência de ações objetivando a coesão das forças internas. Uma estratégia bem formulada ajuda a ordenar e alocar os recursos da organização numa postura única e viável isto baseado nas competências e deficiências internas, na antecipação às mudanças do meio externo e movimentos contingenciais dos concorrentes. (MINTZBERG; QUINN, 1996)
}

Para o desenvolvimento e a formulação do planejamento estratégico torna-se extremamente relevante que a empresa tenha bem estabelecida a forma como irá competir, para que consequentemente tenha objetivos, metas e políticas bem traçadas para o alcance da estratégia. Nesse sentido, a empresa deve analisar não apenas suas características internas como também o ambiente externo em que está inserida e seus concorrentes. De acordo com Buchanan e O'Connell (2006), na década de 60 os professores Learned, Andrews e Christensen sugerem a Matriz SWOT (Forças, Fraquezas, Oportunidades e Ameaças) como um modelo de análise dos fatores estratégicos, auxiliando a tomada de decisão em situações complexas. Sendo assim, com a utilização da matriz é possível que a empresa identifique internamente seus pontos fortes e fracos ao mesmo tempo em que monitora as oportunidades e ameaças do ambiente em que está inserida.

Ao analisar a estratégia de negócios, Grant (1995) também aborda estratégia como uma forma de fazer uma relação entre a organização e o ambiente externo. Sobre a organização, destacam-se três características chaves: seus objetivos e 
valores, seus recursos e capacidades e a estrutura organizacional e de sistemas. Já no ambiente externo, existem fatores econômicos, sociais, políticos e tecnológicos que influenciam a performance de uma empresa e suas decisões. Dessa forma, o autor destaca que, analisar a competição e a concorrência vai muito além do que descrever o ambiente externo no qual a empresa se insere, mas sim analisar o processo interativo dos competidores através de suas iniciativas estratégicas e suas reações frente às iniciativas de outras empresas.

Devido à diversidade de conceitos e definições para estratégia, Mintzberg (2000) destaca que diversas escolas de estratégia foram formadas ao longo das décadas com a finalidade de promover uma vantagem competitiva das empresas frente aos seus concorrentes. Dentre essas escolas, segundo o mesmo autor, a que obteve maior destaque, no sentido de implementação de seus resultados nas realidades das empresas, foi a Escola do Posicionamento, cujo principal autor foi Michael Porter, na década de 80.

Sendo assim, utilizando como base os autores destacados nesta fundamentação teórica, as principais escolas de estratégia e seus respectivos processos, assim como os principais marcos da sustentabilidade, foram consolidados em uma linha do tempo apresentada na Figura 3.

Figura 3 - Evolução dos principais marcos da sustentabilidade e da estratégia na linha do tempo

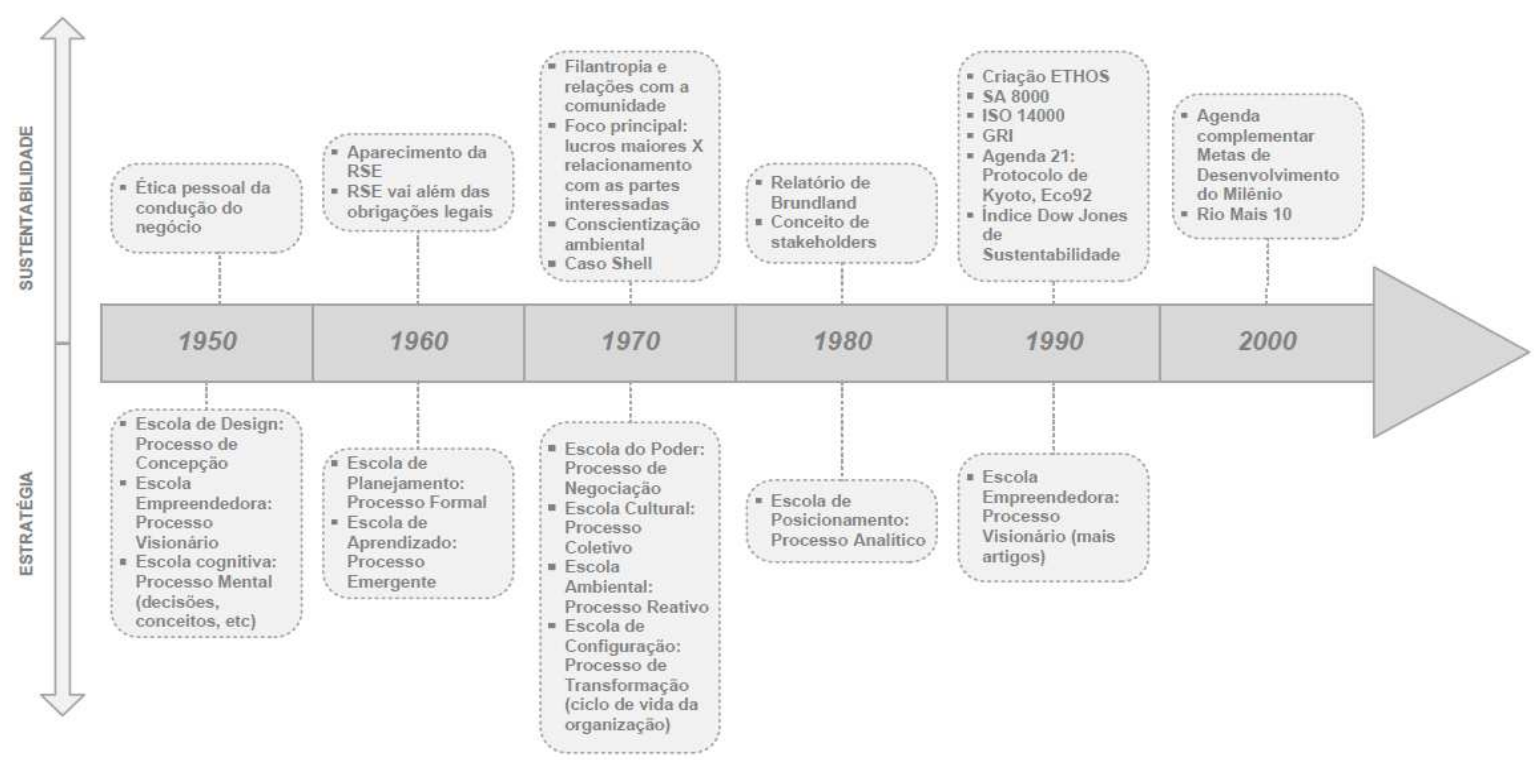

Fonte: Elaborado pelos autores 
A partir da linha do tempo traçada, torna-se possível compreender melhor a evolução dos temas pesquisados ao longo do tempo, tanto em relação aos marcos relacionados à sustentabilidade e suas abordagens, bem como os conceitos e escolas de estratégias que foram desenvolvidos nas últimas décadas.

\subsection{Vantagem Competitiva}

Com o avanço da tecnologia, da globalização e da sociedade, as fronteiras mercadológicas se tornaram mais bem definidas, fomentando uma corrida por vantagens comparativas. Com isso, cabe às empresas buscar mercados inexistentes a baixos custos e a alta agregação de valor ao cliente para se destacar na indústria e alcançar uma vantagem competitiva (KIM, MAUBORGNE, 2005).

Grant (1995) afirma que uma das formas das organizações serem bem sucedidas na manutenção de uma vantagem competitiva é por meio da diferenciação estratégica, que deve ir além das alterações no produto, incluindo todos os aspectos da relação entre os consumidores e as empresas ofertantes. Por isso, o autor sugere que para obter vantagem competitiva por meio da diferenciação, devem ser analisados a empresa e o produto segundo duas perspectivas: o da demanda e o da própria organização. Analisar segundo a perspectiva do consumidor significa determinar quais características do produto tem o potencial para criar valor para o cliente e quanto o cliente está disposto a pagar por elas. Já em relação à perspectiva da organização, a empresa precisa desenvolver suas funções de forma a promover sua singularidade no mercado, seja com base nas características de seu produto e tecnologia, nos serviços complementares, na experiência dos colaboradores, na produtividade, na qualidade, dentre outros aspectos organizacionais.

Além disso, segundo Porter (2005), a manutenção da competitividade depende da estratégia que a empresa pretende adotar frente aos seus concorrentes: diferenciação de seus produtos, liderança no custo total ou enfoque. Para o alcance da diferenciação, a empresa deve gerir seu processo produtivo e sua estratégia de negócio de forma a manter a inovação e a melhoria contínua em suas operações frente aos seus concorrentes. Enfatizando este ponto de vista, Barney (1997) aponta 
que a organização que busca a agregação de valor e a raridade em seus produtos e serviços, a difícil imitação de seus recursos e uma estrutura interna voltada aos objetivos do negócio, tendem a manter posições pioneiras em longo prazo. Já a estratégia de liderança nos custos enfatiza o ganho de competitividade por meio da obtenção de retornos maiores da empresa perante seus concorrentes, devido à redução e controle dos custos totais da empresa. Ademais, segundo Porter (2005), a estratégia baseada no enfoque de um segmento particular do mercado permite uma vantagem competitiva, seja pela adoção de produtos diferenciados ou por baixos custos produtivos.

Sendo assim, Hax e Wilde (2001) propõem um modelo que complementa a visão de obtenção e manutenção da vantagem competitiva por meio da diferenciação do produto ou liderança em custos: o Modelo Delta. Os autores apontam que essas estratégias são significativas em um estágio inicial para que a empresa se enquadre num determinado segmento de mercado, configurando assim, o primeiro vértice do modelo. Entretanto, essas estratégias tendem à comoditização do produto, tornando o grau de ligação entre a empresa e o cliente fraco. Por isso, para obter vantagem competitiva, os autores apontam que a organização deve ir além, buscando formas de suprir as necessidades dos consumidores por meio das ligações com seus fornecedores e, desta forma, alcançando o segundo vértice do modelo.

Por fim, no último estágio de evolução, ou no terceiro vértice do modelo, a empresa deve obter um elo forte com toda sua cadeia de valores do negócio, promovendo lock-in de empresas complementares e lock-out de organizações concorrentes. Neste patamar de evolução, além da empresa possuir foco no produto, nos clientes e nos fornecedores, busca-se também os complementadores, objetivando o ganho no sistema como um todo com seu vasto portfólio. Por isso a inovação tende a gerar sistemas muito mais complexos e difíceis de serem substituídos, resultando uma vantagem competitiva duradoura.

Ademais, Grant (1995) afirma que, independente da estratégia adotada, a vantagem competitiva somente é efetiva e gera rentabilidade se comunicada e percebida pelos consumidores. Com isso, ressalta-se o valor da marca, que é considerada um dos bens intangíveis mais importantes que uma organização pode 
investir. Por meio de uma imagem valorizada, a empresa pode entrar em novos mercados com um diferencial que possivelmente suas concorrentes não o teriam.

Em seu estudo sobre as nações, Porter (1993) afirma que devido às influências e às imposições do governo e do acaso sobre os determinantes da vantagem competitiva nacional, as nações devem se antecipar às solicitações do mercado para se manter em posição de destaque. Essa conclusão pode ser facilmente replicada para a realidade empresarial, onde às empresas devem se antecipar às solicitações do mercado que, conforme observado inicialmente na revisão da literatura deste artigo, estão voltadas à crescente exigência da sociedade para uma indústria embasada em ações sustentáveis. Com isso, Porter (1995) indica que o principal desafio para a obtenção de vantagem competitiva é por meio do mapeamento de ações sustentáveis que sejam direcionadas à agregação de valor para toda a cadeia em que a organização se insere (PORTER, 1995). No trecho abaixo destacado de uma entrevista realizada junto a Michael Porter pode ser observada a importância da sustentabilidade como uma forma de vantagem competitiva:

As empresas estão perdendo dinheiro porque ainda não aprenderam a enxergar a responsabilidade corporativa como algo estratégico... quebrar essa barreira será crucial para a sobrevivência das companhias no futuro. (PORTER, 2010)

Por fim, Nidumolu, Prahalad, Rangaswami (2009) enfatizam a necessidade das empresas tornarem sua cadeia de valor sustentável, cobrando resultados dos fornecedores e percebendo novas formas de parceria, redução de custos, inovação, aumento da eficiência e novos negócios. Desta forma, segundo Hirotaka e Takeuchi (2008), a organização pode encontrar uma forma de diferenciação de valor baseada em seu know-how para manter uma vantagem competitiva sustentável em longo prazo.

\section{RESULTADOS}

Para a realização da análise dos resultados, estes foram divididos em quatro grupos principais: (i) Evolução da produção científica, (ii) Veículos de publicação e 
centros de pesquisa; (iii) Pesquisadores e (iv) Redes de estudo. A seguir, tem-se a análise de cada um deles.

\subsection{Evolução da produção científica}

A Figura 4 apresenta a evolução dos artigos publicados sobre o tema da sustentabilidade como uma vantagem competitiva para as empresas. Percebe-se que esse assunto passou a ter maior foco na atenção dos cientistas por volta do ano de 2000 e que a partir de então, houve um significativo crescimento ao longo dos anos das publicações sobre este tema.

Figura 4 - Evolução da publicação de artigos por ano sobre o tema

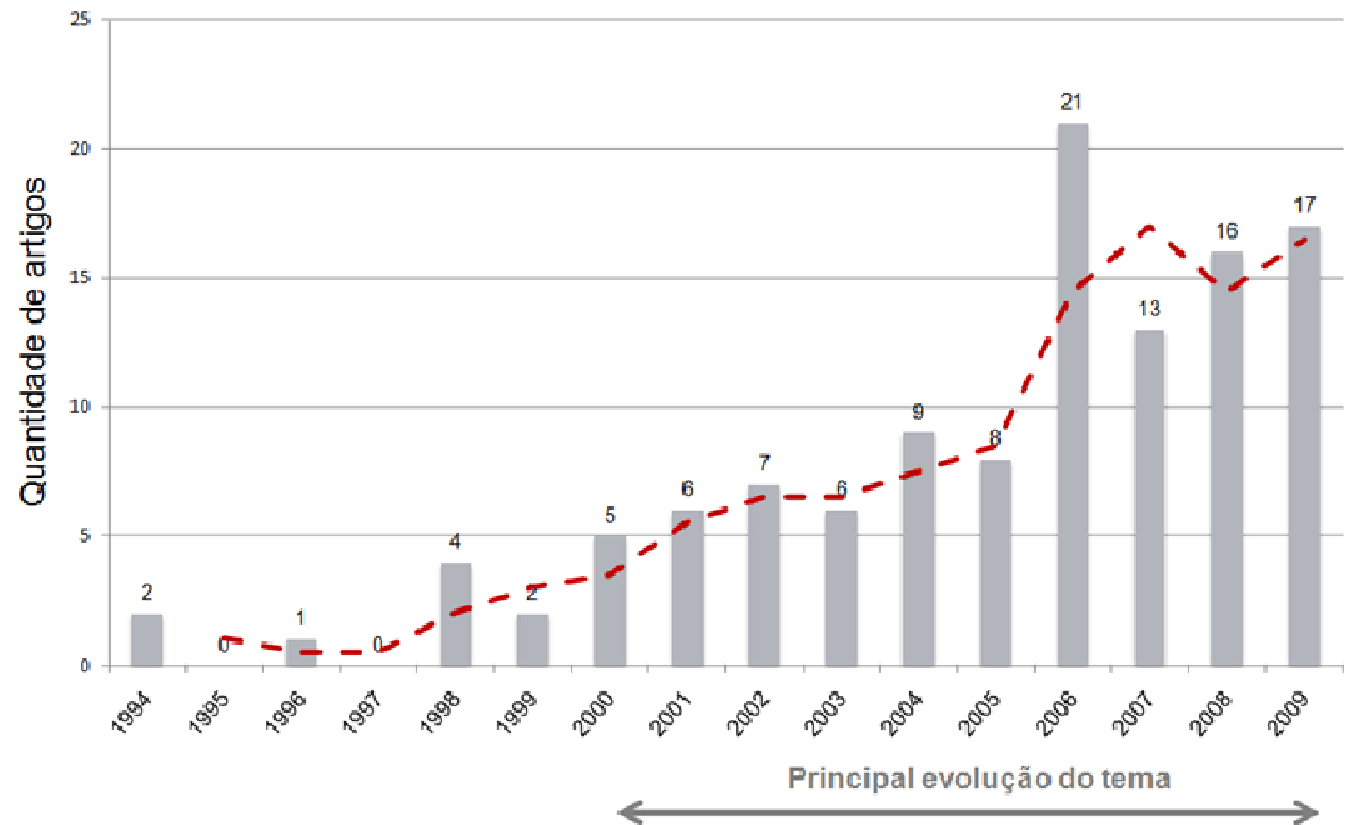

Fonte: Elaborado pelos autores

Como percebido na revisão da literatura, os temas "sustentabilidade" e "vantagem competitiva" configuram assuntos recentes, em que seus principais marcos históricos são observados na década de 80. Por isso, existe uma fundamentação lógica de que o início do crescimento da publicação desses temas em conjunto seja a partir da década de 2000, ou seja, duas décadas após esses principais marcos dos temas em separado. 
Além disso, foi observado na amostra existente que $91 \%$ das publicações se deram por jornais, $7 \%$ foram resultados de conferências e $2 \%$ de outras formas de publicação. Conforme observado na Figura 5, a maior parte desses documentos foi publicada na área de ciência de negócios e administração, seguida, respectivamente pelas áreas do Triple Bottom Line, ou seja, nas ciências ambientais, sociais e econômicas. Com isso, é observado que o enfoque deste tema está vinculado às pesquisas na área de gestão e imagem organizacional, recebendo pouco investimento na estruturação de sua base técnica.

Figura 5 - Principais áreas de ciência que publicaram o tema

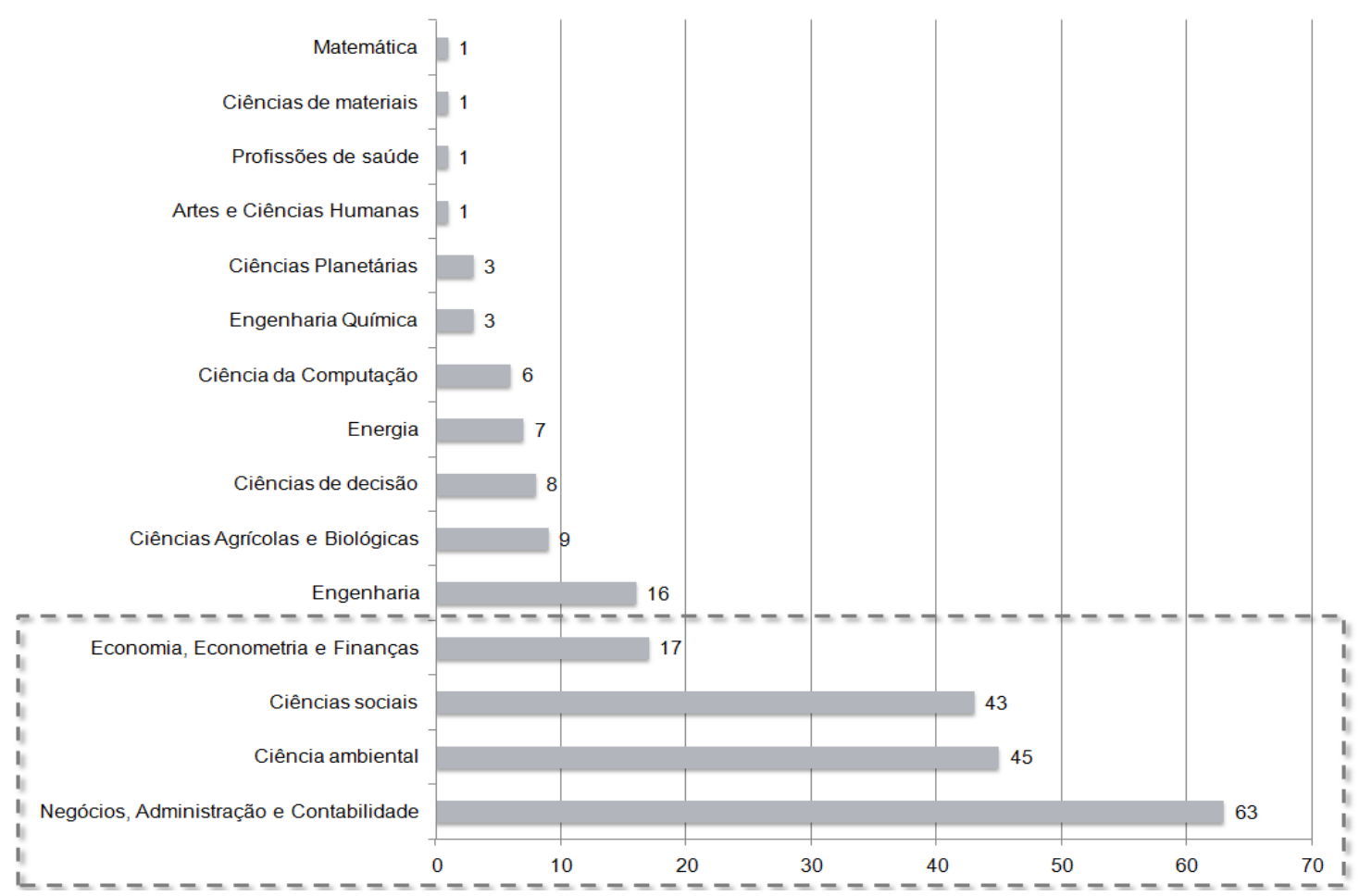

Fonte: Elaborado pelos autores

Além disso, a Figura 5 sinaliza que dentre as principais áreas gerenciais que publicaram sobre o tema, o campo econômico foi o que obteve menos da metade de artigos da amostra quando comparada à ciência anterior, que é representada pelo pilar social. Com isso, constata-se uma carência de publicações acadêmicas na produção de estudos que relacionam as vantagens competitivas originárias da sustentabilidade em relação às questões econômicas e financeiras da indústria. 
As palavras-chave mais citadas pelos autores nas publicações dos artigos dentro deste tema foram respectivamente: sustentabilidade, desenvolvimento sustentável, responsabilidade social empresarial, estratégia, planejamento estratégico, competitividade, inovação e vantagem competitiva.

Com isso, reafirma-se a tendência observada na revisão da literatura, de que a sustentabilidade está tomando cada vez mais um viés proativo em detrimento do foco reativo. Isso pode ser percebido com a alta reincidência da palavra "planejamento estratégico" como um termo-chave nas publicações. Igualmente, vale destacar que o tema "inovação" configura um assunto novo no meio acadêmico e empresarial e que já está sendo abordado junto ao tema deste estudo.

\subsection{Veículos de publicação e centros de pesquisa}

Foi verificado que as principais instituições ofertantes desse tema de pesquisa se encontram no Reino Unido, nos Estados Unidos da América, no Canadá e na Suíça. Ademais, $42 \%$ dos autores possuem como seus países de origem o Reino Unido e os Estados Unidos. Conforme destacado na Figura 6, excluindo as nações citadas anteriormente, não foram percebidas altas taxas de publicação nos demais países, sinalizando que existem poucos centros de pesquisa voltados para o tema. 
Figura 6 - Países de origem dos autores

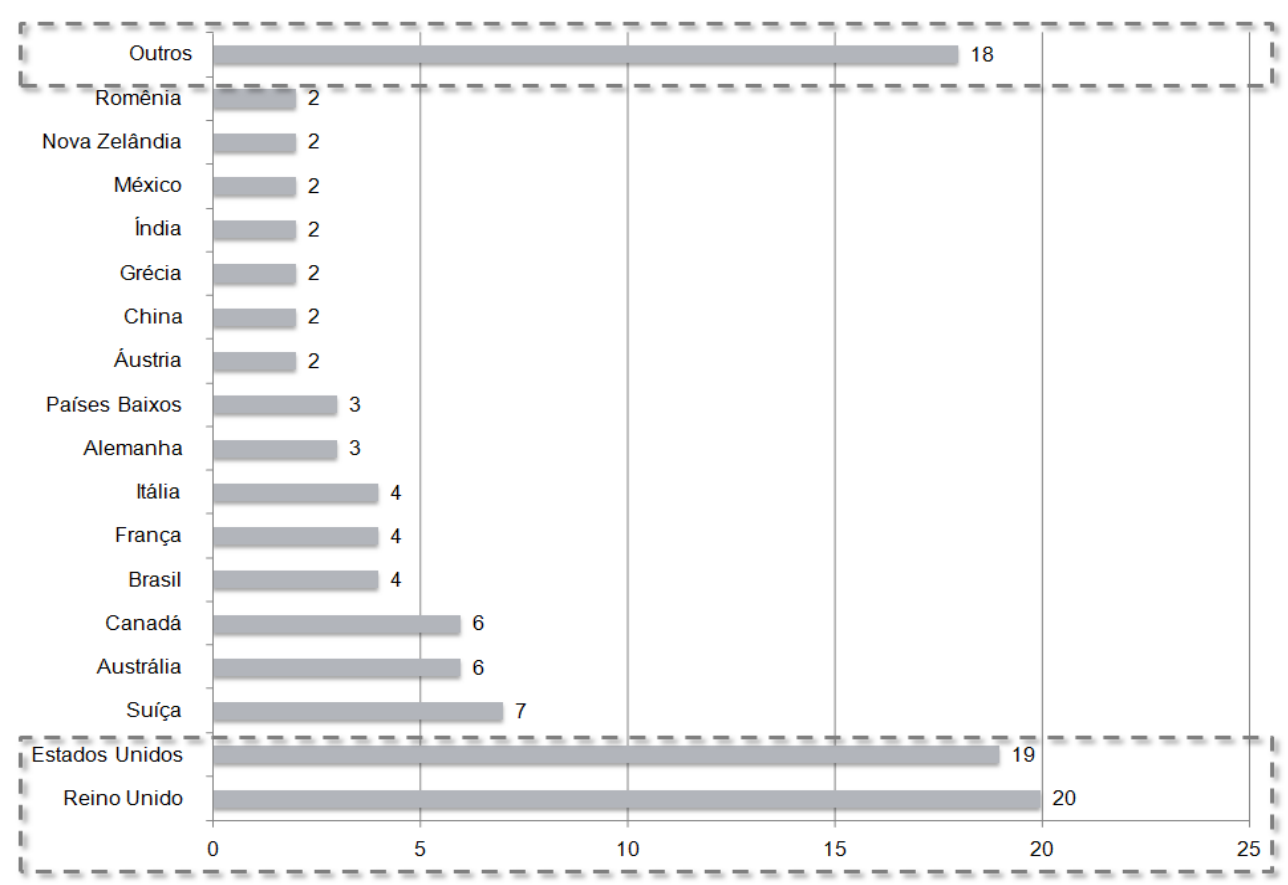

Fonte: Elaborado pelos autores

Já em relação aos veículos de publicação, constatou-se que os jornais que mais publicaram sobre o assunto possuem suas origens no Reino Unido, na Holanda, nos Estados Unidos e na Finlândia, respectivamente.

Com isso, a fim de confirmar a relação entre os países que se destacaram como meios de pesquisa sobre o assunto deste trabalho e a evolução de suas nações, foram analisadas suas colocações em índices que apontam, quantificam e comparam a evolução dos países, tais qual o índice de GINI e o Índice de Desenvolvimento Humano (IDH).

O índice de GINI faz parte de um esforço conjunto entre a Organização das Nações Unidas (ONU) e a Central Intelligence Agency (CIA). Este esforço consiste em calcular os coeficientes de GINI dos países, de forma a realizar uma comparação entre as nações com menores e maiores desigualdades sociais (CIA, 2010). Este relatório teve como resultado que as menores desigualdades se encontram na Eurásia e na América do Norte, respectivamente. Já o índice IDH realiza uma comparação da qualidade de vida entre os países, segundo três perspectivas: Produto Interno Bruto (PIB) per capita, expectativa de vida ao nascer e possibilidade de desenvolvimento intelectual da população. Segundo uma lista divulgada pelo Programa das Nações Unidas para o Desenvolvimento (PNUD, 2010), os países 
listados neste artigo encontraram-se entre as 25 primeiras nações neste índice no ano de 2009.

Em contrapartida, foi observado que os países que tendem a constituir os líderes do crescimento da economia mundial após a crise financeira de 2007 (MANTEGA, 2010), os BRIC (Brasil, Rússia, Índia e China), apresentaram menores índices de publicação sobre o tema. Entretanto, ressalta-se que pesquisas sobre 0 tema objeto de estudo deste artigo representa o interesse dos países em obter crescimento econômico em conjunto à sustentabilidade ambiental e social, sendo assim, não pode ser comprovado sobre a perspectiva deste estudo o interesse do BRIC neste equilíbrio ao longo de seu crescimento.

Em relação ao fator de impacto ou Journal Citation Report (JCR), os veículos de publicação apresentaram um baixo número médio de vezes em que os artigos das revistas publicadas foram citados nos últimos anos. Entretanto, as citações utilizadas pelos autores possuem um alto JCR, sendo que os jornais mais utilizados como referência foram: Academy of Management Review, Strategic Management Journal e Harvard Business Review.

\subsection{Pesquisadores}

Os pesquisadores tidos como principais referenciais nas pesquisas com o tema de sustentabilidade como uma vantagem competitiva foram Michael Porter e Prahalad. Porter foi pioneiro na escola de posicionamento, conforme ressaltado no capítulo da revisão de literatura. Já Prahalad, realizou estudos sobre as mudanças no panorama mundial de negócios, ressaltando a importância do consumidor na base da pirâmide.

Além disso, nota-se que o autor Michelini também aparece como um dos mais citados nos artigos e, apesar de não ter a notoriedade de Porter e Prahalad, também desenvolveu importantes estudos na área de sustentabilidade. A lista dos autores mais citados encontra-se na Tabela 1. 
Tabela 1 - Lista de autores mais citados como referências

\begin{tabular}{lc|lc}
\multicolumn{1}{c}{ Autores mais citados } & Citações & \multicolumn{1}{c}{ Autores mais citados } & Citações \\
Porter, M.E. & 31 & Shrisvastava, P. & 13 \\
Hart, S. & 24 & Elkington, J. & 13 \\
Michelini, R.C. & 17 & Schaltegger, S. & 13 \\
Prahalad, C.K. & 16 & Welford, R. & 13 \\
Zadek, S. & 15 & Wagner, M. & 11 \\
Wheeler, D. & 15 & Hatchuel, A. & 11 \\
Hamel, G. & 14 & Sharma, S. & 10
\end{tabular}

Fonte: Os Autores

\subsection{Redes de estudo}

Percebeu-se pouca quantidade de autores por artigo, bem como poucas instituições de pesquisa por documento, conforme mostrado na Figura 7. Assim, constata-se que, por se tratar de um assunto recente, ainda não foram formadas grandes parcerias para o estudo do tema.

Figura 7 - Quantidade de autores por artigo e de instituições de pesquisa por artigo
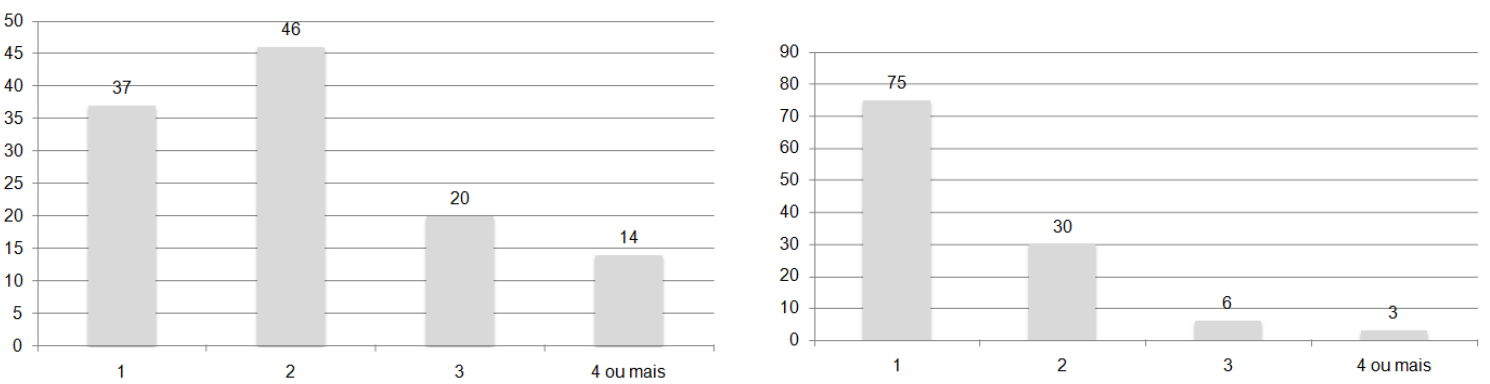

Fonte: Elaborado pelos autores

\section{CONCLUSÃO}

Conforme observado na revisão da literatura, para uma organização possuir competitividade no mercado é necessário romper o paradigma de que a vantagem competitiva está embasada apenas na perspectiva econômica e passar a desenvolver os pilares sociais e ambientais em sua cadeia produtiva. Desta forma, a empresa pode alcançar a redução de custos, o aumento da qualidade, parcerias, benefícios das partes interessadas e novos negócios que podem sustentar uma vantagem competitiva em longo prazo. 
Com base na metodologia desenvolvida para a implementação de uma análise bibliométrica acerca de publicações sobre a sustentabilidade como um meio para atingir a vantagem competitiva, este artigo alcançou os objetivos e questões de pesquisa expostos no capítulo de introdução.

Primeiramente, foi percebido um aumento recente das publicações sobre 0 tema deste artigo, principalmente a partir do ano 2000. As áreas da ciência que mais publicaram sobre o assunto são as representadas pelo Triple Bottom Line (ambiental, social e econômica), assim como as ciências de administração e de negócios. Dentre essas ciências, a área econômica é a que menos investe em estudos sobre o tema. Sendo assim, foi observado um maior quantitativo de publicações nas áreas gerenciais e de imagem organizacional, com uma menor ênfase na estruturação do tema por meio de linhas de pesquisa em áreas técnicas.

Em relação às palavras-chave citadas nos artigos, constatou-se que a sustentabilidade está cada vez mais passando de um caráter reativo a um proativo, ao ter alta incidência de termos como "planejamento estratégico" e "inovação". Além disso, constatou-se que os países que possuem os melhores índices de desenvolvimento, tal qual o IDH e o índice GINI, são os pioneiros na publicação deste tema. Em contrapartida, os países que possuem maior previsão de crescimento - os BRIC - possuem menos trabalhos publicados na área. Já os jornais utilizados como veículo de publicação possuem baixo fator de impacto, embora os estudos utilizados como referência possuam grande aceitação pelo meio acadêmico.

Ao final, foram constatadas poucas parcerias de estudo tanto entre instituições de pesquisa quanto entre autores. Acredita-se que essa fraca rede de estudo está associada à recente abordagem do tema. Por fim, enfatiza-se que esta pesquisa científica teórica proporciona uma visão holística sobre as produções acadêmicas de sustentabilidade como um meio de obtenção de vantagem competitiva. Este artigo não pretende fornecer uma análise detalhada da implementação deste tema, mas sim um entendimento do meio científico de forma a embasar aprofundamentos de estudos futuros sobre o tema. 


\section{REFERÊNCIAS}

ABNT - Associação Brasileira de Normas Técnicas. NBR ISO 14001: Sistemas de Gestão Ambiental - Especificação e diretrizes para uso. Brasil, 2004.

ARAÚJO, C. A. Bibliometria: evolução histórica e questões atuais. Em Questão, Porto Alegre, v. 12, n. 1, p. 11-32, jan./jun. 2006.

BARNEY, J. B.. Gaining and sustaining competitive advantage. Reading, MA: Addison-Wesley, 1997.

BOVESPA. ISE: Índice de sustentabilidade empresarial. São Paulo, 2008.

Disponível em: <Índice de Sustentabilidade Empresarial - ISE | BM\&FBOVESPA>. Acesso em 28 jun. 2010.

BP (British Petroleum). Site da empresa British Petroleum. Disponível em < $\underline{\text { Gulf of }}$ Mexico restoration $\mid \mathrm{BP}>$. Acesso em: 30 set. 2010.

BUCHANAN, L.; O'CONNELL, A. A brief history of decision making. Harvard Business Review, v.84, n.1, p.32-41, 132, jan. 2006.

CAPRA, F. Os desafios do século XXI: as conexões ocultas: ciência para uma vida sustentável. São Paulo: Cultrix, 2005, p.109-289.

CIA - Central Intelligence Agency. Field listing: distribution of family income - Gini index. Disponível em: <https://www.cia.gov/library/publications/the-worldfactbook/fields/2172.html>. Acesso em: 29 abr. 2010.

DAILY, F.B.; HUANG, S.. Achieving sustainability through attention to human resource factors in environmental management. New Mexico, USA: New Mexico State University, 2001.

FARIAS FILHO, José Rodrigues de. Ensaio teórico sobre pesquisa bibliográfica em estratégia de operações. Niterói: UFF/TEP, 2009. (Apostila da Disciplina de Gestão de Operações - Programa de Pós-Graduação em Engenharia de Produção).

FIESP - Federação das Indústrias do Estado de São Paulo. Gestão ambiental. São Paulo, 2010. Disponível em: <http://www.fiesp.com.br/ambiente/ area_tematicas/gestao_ambiental.aspx>. Acesso em: 18 jul. 2010.

FORTES, Marcel. Ação global e o papel do investimento social privado na questão da inclusão social. Aracaju, 2006. Palestra proferida em evento do Movimento Competitivo Sergipe. Disponível em: $<$ MCS - Movimento Competitivo Sergipe >. Acesso em: 4 jul 2010.

FUJIHARA, M. A.. Gestão da sustentabilidade do empreendimento. Disponível em:<www.acionista.com.br/mercado/sustentabilidade>. Acesso em: 29 abr. 2010. 
GANDHI, N.M.; SELLADURAI, V.; SANTHI, P.. Unsustainable development to sustainable development: a conceptual model. Coimbatore, India: Kumaraguru College of Technology, 2006.

GRANT, Robert M. Comtemporary strategy analysis: concepts, techniques, applications. Cambridge. Blackwell Publishers. 1995. Páginas $276-300$

GRI. Directrizes para a elaboração de relatórios de sustentabilidade. Holanda, 2007. Disponível em: <GRI - Home Page $>$. Acesso em: 01 jul. 2010.

GÜNTHER, Wanda. Minimização de resíduos e educação ambiental. Curitiba: Seminário Nacional de Resíduos Sólidos e Limpeza Pública, 2000.

HAYS, R.; PISANO, G; UPTON, D.; WHEELWRIGHT, S.. Estratégia de produção: origens e novas orientações: em busca da vantagem competitiva. Porto Alegre: Bookman, 2008, p.57-93.

HAX, Arnold C.; WILDE, Dean. The delta project: Discovering new sources of profitability in a networked economy. New York: Palgrave, 2001. Páginas 7-49 e 105119.

HIROTAKA, I.; TAKEUCHI, N.. Diferenciação de valor: organização do know-what para a inovação do conceito de produto. gestão do conhecimento. Porto Alegre: Bookman, 2008, p.142-165.

INSTITUTO ETHOS. O que é RSE. São Paulo, 2010. Disponível em: <lnstituto Ethos>. Acesso em 4 jun. 2010.

JOHN, Vanderley; SILVA, Vanessa; AGOPYAN, Vahan. Agenda 21: uma proposta de discussão para o construbusiness brasileiro. Rio Grande do Sul: ANTAC, 2001.

KIM, W.C.; MAUBORGNE, R.. A estratégia do oceano azul. São Paulo: Elsevier, 2005.

MINTZBERG, H.. Safári da estratégia. Porto Alegre: Bookman, 2000.

MANTEGA, G.. Para Mantega, Brics serão líderes de crescimento. Guia Exame de Economia. Disponível em:

$<$ http://portalexame.abril.com.br/economia/noticias/mantega-brics-serao-liderescrescimento-570593.html>. Acesso em: 17/08/2010.

MINTZBERG, H. \& QUINN, J. The strategy process: concepts, contexts, cases. New Jersey: Prentice-Hall, 1996. 900p

NIDUMOLU, R.; PRAHALAD, C. K.; RANGASWAMI, M. R.. Por que a sustentabilidade é hoje o maior motor da inovação. Boston, EUA: Harward Business School, 2009. 
PACTO GLOBAL REDE BRASILEIRA. The global compact. São Paulo, 2008. Disponível em: < Pacto Global Rede Brasileira>. Acesso em 01 jun. 2010.

PAO, M. L. Concepts of information retrieval. Englewood, Colorado:Libraries Unlimited, Inc., 1989. 285 p.

PNUD - Programa das Nações Unidas para o Desenvolvimento. PNUD divulga novo estudo e IDH. Disponível em: <PNUD Brasil :.:. | CIDADANIA | REPORTAGENS | INDEX>. Acesso em: 29 abr. 2010.

PORTER, M.. Determinantes da vantagem competitiva nacional. Rio de Janeiro: Campus, 1993.

PORTER, M.. Parem de gastar tanto dinheiro: guia exame de sustentabilidade. Disponível em:

<http://planetasustentavel.abril.com.br/noticia/desenvolvimento/conteudo_265708.sht ml?func=2>. Acesso em: 24 ago. 2010.

PORTER, Michael E. A vantagem competitiva das nações. Rio de Janeiro: Campus, 1993. Páginas: 85-159.

PORTER, M.; VAN DER LINDE, C. Verde competitivo: acabando com o impasse. Competição: estratégias competitivas essenciais. Rio de Janeiro: Campus, 1995.

PORTER, M. Estratégia competitiva: técnicas para análise da indústria e concorrência. Rio de Janeiro: Campus, 2005.

SAM Group. Dow Jones sustainability world indexes guide. Suíça, 2008. Disponível em: <www.sustainability-indexes.com>. Acesso em: 03/07/08.

SIFF - SOCIAL INVESTMENT FORUM FOUNDATION. Socially responsible investing trends in the united state. Estados Unidos, 2009. Disponível em: < Social Investment Forum: SRI Research - Trends, SRI Industry Reports, \& Moskowitz Prize Papers>. Acesso em: 5 mar 2010.

VIOLA, Eduardo. O regime internacional de mudança climática e o Brasil. São Paulo: Revista Brasileira de Ciências Sociais, 2008.

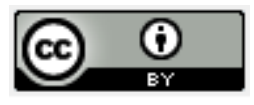

Artigo recebido em 15/04/2011 e aceito para publicação em 20/12/2011. 